\title{
It's not how you finish, it's how you start?
}

\author{
Sudish C. Murthy, MD, PhD
}

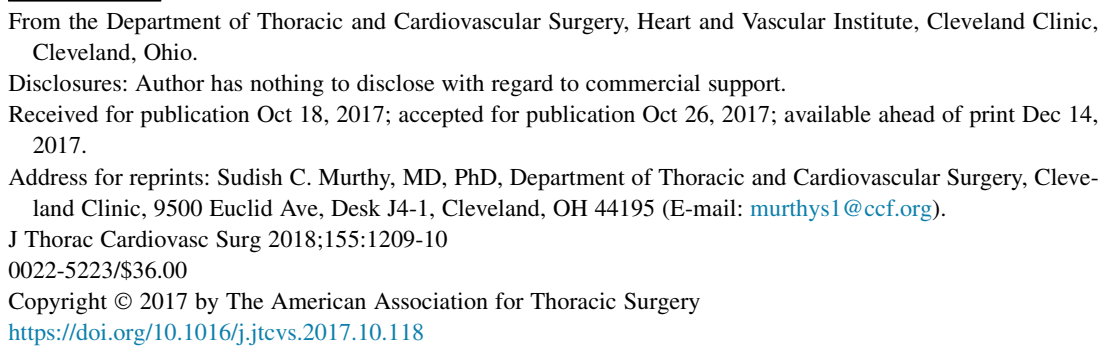

From the Department of Thoracic and Cardiovascular Surgery, Heart and Vascular Institute, Cleveland Clinic, Cleveland, Ohio.

Disclosures: Author has nothing to disclose with regard to commercial support.

Received for publication Oct 18, 2017; accepted for publication Oct 26, 2017; available ahead of print Dec 14, 2017.

Address for reprints: Sudish C. Murthy, MD, PhD, Department of Thoracic and Cardiovascular Surgery, Cleveland Clinic, 9500 Euclid Ave, Desk J4-1, Cleveland, OH 44195 (E-mail: murthys1 @ ccf.org).

J Thorac Cardiovasc Surg 2018;155:1209-10

$0022-5223 / \$ 36.00$

Copyright (c) 2017 by The American Association for Thoracic Surgery

https://doi.org/10.1016/j.jtcvs.2017.10.118

In this issue of the Journal, Fernandez and colleagues ${ }^{1}$ offer some insight into the late impact (out to 18 months) of early complications after lung cancer surgery. I can imagine this being troubling to our patients; now, not only do they need to worry about their lung cancer returning after a definitive therapeutic intervention, they also need to be concerned with how well they recover from that intervention as a potent predictor of late mortality. Just when patients think that the worst is behind them in terms of their recovery, we may have to tell them that the worst is actually in front of them, and it may have nothing to do with their cancer. Truly unfair!

This study is based on a complex marriage between the Society of Thoracic Surgeons database and Medicare data, which has allowed some of the far-reaching effects of perioperative complications to be scrutinized and their impact on late mortality to be addressed. Sepsis after lobectomy is no doubt a risk to immediate postoperative survival. Does it, however, somehow, in some way, cause some late mortality, presumably even as late as 18 months after recovery? It just may. Moreover, can a blood transfusion given during the perioperative period place a patient at risk for death well over a year from the operation? This, too, just may be the case.

Before we completely change the way we obtain consent from patients to include all the risks of lobectomy for lung cancer, now including preparation for late mortality risks that are based completely on future events that may or may not happen, there are a few nuances to this analysis that need to be appreciated. First, the Medicare database is just that, the Medicare database, and patients not yet participating in Medicare coverage are not in it. Thus, there is obligate censoring of a significant number of patients in our Society of Thoracic Surgeons database when the databases are combined, and this presumably extricates from the analysis the younger, perhaps healthier, patients who are gainfully employed and whose coverage is provided through a non-Medicare insurance product.

In addition, no context is given for any of these complications. Would a perioperative pneumonia in a patient who as never smoked and has normal spirometry and lepidic

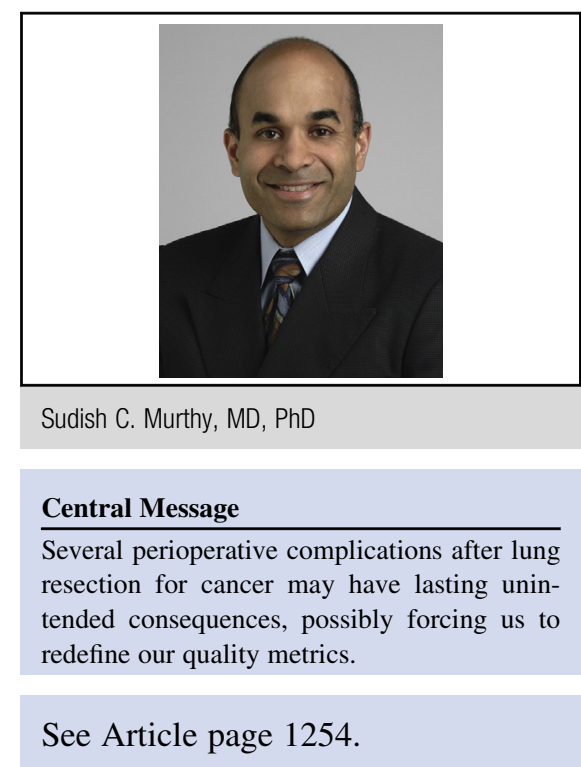

or mucinous adenocarcinoma be expected to have the same short- and intermediate-term impact as it might if occurring in a patient who is heavy current smoker and has marginal pulmonary function and solid or micropapillary histologic type? We simply do not have the granularity in our Society of Thoracic Surgeons database to risk stratify for the impact of these complications. Dependence of the complications on patient factors is clearly critical, as is their interdependence among each other, and going forward, I suspect there will have to be additional data fields collected to address this.

How might we use these data? If one believes that a perioperative transfusion might result in a late death, do we avoid one at all costs, even when it is deemed necessary? What about for patients who have undergone induction therapy for locally advanced disease and are anemic at the time of their index operation? And if a patient has one of these dreaded complications during the perioperative course, should we perform follow-up more vigilantly in the postoperative period for cancer recurrence or for some other health-related issue that might lead to death?

Finally, do we need to rethink how we measure quality of a lung cancer resection? Reintubation for respiratory failure and return to an operating room after lobectomy are no doubt significant complications and should negatively affect quality assessments. However, because of the farreaching negative effect of perhaps just a single unit of blood transfused in the perioperative period, should this somehow be a more important metric when considering quality? 
As with most good studies, more questions are raised than answered here, but they are important questions. Provocative as they are, paradigm changing they may very well be. There are other examples of how a slow start after a major surgical intervention can have important negative downstream effects, and lung transplant surgeons are acutely aware of this. To summarize, we are all familiar with the phrase, "It's not how you start, it's how you finish!" But perhaps we have got it backwards.

\section{Reference}

1. Fernandez FG, Kosinski AS, Furnary AP, Onaitis M, Kim S, Habib RH, et al. Differential impact of operative complications on survival following surgery for primary lung cancer. J Thorac Cardiovasc Surg. 2018;155:1254-64. 